This is the peer reviewed version of the following article: Howitt SM, Wilson AN. Reflecting on the use and abuse of scientific data facilitates students' ethical and epistemological development. Science Education 2018;102:571-592, which has been published in final form at https://doi.org/10.1002/sce.21333. This article may be used for noncommercial purposes in accordance With Wiley Terms and Conditions for self-archiving. 


\title{
Reflecting on the use and abuse of scientific data facilitates students' ethical and epistemological development
}

Susan Howitt, Australian National University, and Anna Wilson, University of Stirling

\begin{abstract}
Scientists use judgment in deciding what and how much data to present in publications but science degrees rarely address this issue. Instead, scientific knowledge is presented as certain and students have limited opportunities to use their own judgment in the laboratory. A consequence of this may be that students approach science with a moral absolutist mindset, believing that science is about learning facts and scientists have little need to exercise ethical judgments in relation to data. Students may also hold different ethical standards for themselves and professional scientists. We draw on data from a first-year science module to show that these views can be challenged by encouraging students to reflect on their own behaviour and that of famous scientists in situations with varying degrees of professional ethical ambiguity. We provide evidence of significant transitions in students' thinking, suggesting that reflection on these issues may lead to substantial epistemological and ethical development. By the end of the module, many students had moved from an initial position of certainty to the acceptance of multiple viewpoints or to a more mature understanding of the evidence-based nature of science, as well as gaining the ability to critique decisions and make ethical judgments.
\end{abstract}




\section{Introduction}

The exercise of judgment in the presentation and manipulation of data is an important part of the work of a scientist, and one that has a strong ethical dimension. Although scientists constantly make decisions about the rights and wrongs of putting forward particular conclusions and evidence to support them, this is not usually openly addressed in undergraduate science curricula. Instead, many students graduate from a science degree with the impression that science is about truth, that good science leads to unambiguous results, and that only bad science leaves room for doubt and interpretation. This is a problem not only for those who will go on to be practising scientists, but for anyone who wishes to engage with the big scientifically-informed issues facing contemporary society, such as debates around climate change and evolutionary issues, where questions of trust and bias loom large. Here, we analyse the impact of confronting students with cases where famous scientists have dealt with ambiguous data to explore students' conceptions of ethics in data interpretation.

Manipulation of data, and the point at which it becomes fraudulent, is a fertile issue with which to challenge students because it surfaces the need to make judgments in an area of interest to them. The generation of publishable data by scientists is a negotiated process that relies on expertise to include or exclude particular results (Latour \& Woolgar, 1986; Roth, 2012). Minor levels of manipulation can also be justified as 'tidying up'; this appears to be common practice in the competitive world of science where publication can depend on the perceived clarity and quality of the data (Steneck, 2011). Two key areas of the undergraduate science curriculum where students might engage with such ideas are in their own laboratory work and in subjects which explicitly address the nature and process of science, for example through historical case studies. However, while science degrees have a strong emphasis on practice in the form of 
laboratory and field work, the way these activities are structured often provides limited opportunities for students to use their own judgment and engage in the types of decision-making required of autonomous scientists (Chinn \& Malhotra, 2002; Edmondson \& Novak, 1993; Handelsman et al., 2004). The judgments made in the generation of data could be illustrated by historical studies of actual scientific practice, especially where controversy has occurred, but such approaches are often peripheral to, or absent from, the content-heavy curriculum. Thus, despite the importance of these issues to an understanding of science (Roth, 2012), students are rarely, if ever, exposed to them.

The need to make judgments about data is one aspect of a more general concern with science education; that it fails to address the central role of evaluation and critique (Duschl, 2008; Ford, 2008; Ford, 2015). Scientific knowledge is always scrutinised by the scientist who does the work and then by peers through peer review and subsequent replication and extension. This provides a sociocultural dimension to science as scientific claims are both validated by the community and tested against their value in explaining natural phenomena. Ford (2008) has argued that the focus of many curricula on the acquisition of content knowledge and skills omits the role of both levels of accountability but that it is an essential component of scientific practice and reasoning that students need to understand. He proposes that students should be taught a "grasp of practice", which encompasses both construction and critique of knowledge claims. This would enable students to learn new content in ways that engage them in thinking like a scientist does. Gaining a grasp of practice means that students "know that scientific knowledge is held accountable through its explicit connections to nature's behavior, know how to play the roles of constructor and critiquer appropriately, and know that the interaction of these on the communal level produces reliable scientific knowledge" (Ford, 2008, p416 italics in original). 
Importantly, gaining a grasp of practice includes recognition of the need for judgment. The nature of any professional "practice" is that it cannot be fully defined by a set of rules, even though it may appear to contain regularities (Ford, 2015; Gherardi, 2009). As noted above, scientists make judgments about what data to present (Latour \& Woolgar, 1986; Roth, 2012) and they know that their decisions will be scrutinised by the scientific community. However, what is under-emphasised in the work of Ford, Roth and others is the ethical dimension of those judgments. There are no rules on which to base these decisions; instead scientists use their expertise but may also be influenced by their desire to convince peers, potentially leading to ethical dilemmas.

The institution of science operates through a series of norms that define the behaviour of scientists but within these, there is considerable ambivalence (Merton, 1973; Mitroff, 1974). Science is said to be self-correcting, as errors or fraud are detected through peer review and/or replication (Merton, 1973) but there have been concerns raised about the effectiveness of these processes (Broad \& Wade, 1982). Firstly, in some disciplines repetition and replication of results are unlikely because of the cost of experiments or the need to collect large data sets and secondly, the use of publication metrics to assess performance has increased pressures on scientists to publish, resulting in a focus on novelty and impact rather than confirmation and replication (Ioannidis, 2012; Munafò et al., 2017; Smaldino \& McElreath, 2016). However, while scientists may be seeking recognition through publication, research suggests they are also motivated by a desire to do, and be recognised for, excellent science (Merton, 1973; Mitroff, 1974). Thus, it appears that scientists' judgments about what data to present to others are not just determined by expectations of scientific scrutiny in peer review and by the wider audience, but also by their own views of acceptable conduct. While very few scientists are guilty of outright 
misconduct, many engage in what have been termed "questionable research practices" (Fanelli, 2009). Ethical considerations come into play here because scientists' motives for such practices can range from a gut feeling based on expertise to a desire to support a particular view. When deciding not to publish a data point or result, scientists may be doing so because they believe it is the "right" course of action, one that will benefit the progression of their field and the construction of new knowledge (Mitroff, 1974; Waller, 2002). This decision, however, may arise because of unconscious bias or beliefs (Munafò et al., 2017), resulting in what others might see as the unethical manipulation of data.

As well as helping to position scientists as less than perfectly rational humans, the use and abuse of data is an issue that interests students because they can see how it applies to their own behaviour in practical classes. Students' experiences often include technical problems in the laboratory, where they are faced with decisions such as whether to repeat a failed experiment, use data from another student, make up the expected result, or be rigorously honest and perhaps receive a low mark for having failed to complete the experiment. Previous work has found that students respond to this situation with different expectations for themselves and 'real' scientists; whereas many think it is acceptable for them to share or fabricate data to meet assessment requirements, they have an idealized view of professional science that excludes technical difficulties and holds scientists to the highest ethical standards (Del Carlo \& Bodner, 2004; Vhurumuku, Holtman, Mikalsen, \& Kolsto, 2006). Similar results emerged in a study which examined how chemists' epistemological beliefs varied with their expertise, spanning high school students to professional chemists (Samarapungavan, Westby, \& Bodner, 2006). While a number of issues were addressed, most relevant here is that participants were specifically asked about how they handled empirical anomalies. Students, including postgraduates, tended to see 
anomalies as wholly negative, resulting from personal failure or technical problems. It was only the professional chemists who identified a potentially productive role for anomalies as they recognised that new research directions could arise from an unexpected finding. Similarly, Chinn and Brewer (1993) noted seven responses to anomalous data, ranging from outright rejection to modification of a theory but professional judgment and an understanding of context were required to choose an appropriate response.

These studies raise two issues. First, students do not always recognise a need for judgment in relation to data, with outright rejection appearing to be a default position for unexpected results, and second, where the need for such judgments is recognised, different ethical standards are applied to themselves and scientists, and the ethical dimension inherent in these judgments may not be explicitly recognized at all. This, in turn, raises questions about how students perceive science and what they are actually learning about how science is practised. The existence of two separate views of science has been conceptualised by Hogan (2000), who defined the proximal view as the way science students understand the science they do and the distal view as reflecting student understanding of professional science (Hogan, 2000). The separation of proximal and distal views of science has implications for students' development as scientifically literate citizens and for the way in which they approach learning science (Edmondson \& Novak, 1993; Hogan, 2000). Proximal views may result in a 'right answer orientation' (Hodson, 1999) because science is seen as a body of fixed knowledge and science learning is seen as memorising facts. As long as such a view of science is productive in meeting assessment requirements, students may have little incentive to change (Edmondson \& Novak, 1993; Elby \& Hammer, 2001). Indeed, students' understandings of the nature of science are notoriously difficult to change (Clough, 1997; Lederman, 2007; Matthews, 2012; Sandoval, 2014) and there is therefore a need 
to investigate the reasons for this more thoroughly. Distal knowledge relates to the way students perceive 'real' scientists, who may be seen as discoverers of new knowledge and theories and are often idealised (Hogan, 2000; Howitt \& Wilson, 2014), particularly as professional science may be presented by teachers and textbooks in idealistic and unrealistic ways (Allchin, 2003).

Scientists are therefore not seen as wrestling with the kinds of difficulties students experience as part of learning and doing science. While students see studying science as a separate enterprise from being a scientist, they are unlikely to see the need for professional expertise and judgment.

\section{Theoretical framework}

Our aim in this study was to examine how students develop the ability to make ethical judgments in the use of scientific data. This will depend on both students' perceptions of science and their ability to accept the uncertainty inherent in a need for judgment. Acceptance of uncertainty implies an epistemological stance and the role of epistemic cognition in science learning is an active and growing area of research (reviewed in Bendixen \& Rule, 2004; Elby, Macrander, \& Hammer, 2016; Kelly, McDonald, \& Wickman, 2012; Sandoval, Greene, \& Bråten, 2016; Sinatra \& Chinn, 2012). These reviews make clear that epistemological studies of science learning have developed from different academic traditions, including science education, science studies, psychology and philosophy which have distinct but overlapping theoretical frameworks. Here, we focus our discussion on two dimensions that are important for the current study; the proximal/distal axis, which defines the scientific context in which judgments are made and the personal/developmental axis, which places the student in relation to their ability to accept the contestability of knowledge. 
It might be expected that a university science education would bring proximal and distal views of science together, as students engage with the professional practice of scientists. However, this depends on the degree to which students actually do interact with professional scientists and the way that teaching and learning experiences are designed. Teaching and learning activities may be underpinned by epistemologies very different from those of authentic science (Chinn \& Malhotra, 2002). As a consequence, students may adopt epistemological positions that are productive for meeting assessment requirements (Edmondson \& Novak, 1993; Elby \& Hammer, 2001), but are not necessarily those desired by educators. Epistemological considerations are not always made explicit in curriculum design and thus there is a need to examine the relationship between science learning and epistemological development (Kelly et al., 2012). Recognising that students may have different proximal and distal views of science, and that these are shaped by their experiences of learning science, is fundamental to better assisting students develop their own understanding of what science is and how it is done.

Proximal and distal understandings of science are one way to express the complexities of students' epistemological approaches. We have chosen to use this categorisation because it exemplifies the distinction important to this study; the difference between students' views of themselves as science students and their views of professional scientists when it comes to decisions that might be viewed as forms of data manipulation. However, it is one expression of a more general idea, that students deploy different epistemological resources in different contexts. A review of studies addressing the nature of science distinguishes between enacted views, based on what the students do, and professed views, which include their declarative knowledge about science (Deng, Chen, Tsai, \& Chai, 2011). A distinction has also been made between inquiry learning or scientific practices, which focus on what students do and students' conceptions of the 
nature of science, which reflect their understanding of professional science (Lederman, 2007). Sandoval (2005) adopted an epistemological approach using the terms practical epistemology to describe the way in which students construct and understand their own scientific knowledge through inquiry and formal epistemology to describe students' expressed beliefs about professional science. He argues that although students' practical approach to inquiry may mimic that of scientists, this does not necessarily influence their formal epistemologies and therefore we need to better understand students' practical epistemologies so that we can support their integration into formal epistemologies. Although these studies employ different perspectives and use different terms, taken together they provide compelling evidence that students hold more than one understanding of science and that their different understandings are deployed in different contexts.

The second dimension underpinning students' attitudes to science and science learning is their personal epistemological and ethical development because the ways in which students conceptualise knowledge, and their understandings of how ethics enters into different levels of scientific practice, will impact on their learning behaviours in science. In order to make the transition to 'being a scientist', students need to move from a position where they are receivers of secure, accepted knowledge to a position where judgments can be made because they see themselves as being able to contribute to knowledge construction. They also need to develop a sense of how personal, social and cultural factors can introduce an ethical dimension not just to decisions about what science to practice, but also how to practice it. The role of epistemological development in learning was first identified by Perry (1970) but has been explored by a number of other authors since (reviewed in Hofer \& Pintrich, 1997), with all having in common that such development involves substantial qualitative changes in the nature of learning and how 
knowledge is viewed. In these models, epistemological and ethical development occurs through several key transitions (Figure 1) in which knowledge is initially viewed dualistically, as either right or wrong. The first transition involves the recognition of uncertainty and the existence of multiple opinions but does not yet include the ability to distinguish between them. The next transition recognises the role of evidence and context in justifying one viewpoint over another. In the final transition, which has been recognised as more social and ethical than epistemological (Moore, 2002), the student commits to particular values as a basis for making life decisions.

\section{Insert Figure 1 about here}

Moore (2002) describes the Perry scheme as 'reflect[ing] two central interwoven dynamics: 1) confronting and coping with diversity and uncertainty with respect to new learning, and 2) the attendant evolution of meaning-making about learning and self' (p22). Both of these are highly relevant to our study. Moore also notes that, '[i]n its representations of both intellectual and epistemological perspectives (and their relationships), the model continues to focus our attention on the intimate connections between the individual learner, subject matter, and process of understanding, and remains a rich heuristic framework' (p18). It is this richness and focus on relationships that makes the Perry scheme appropriate for our analysis. Much subsequent work has taken a more restricted view of epistemic cognition that excludes identity and emotion from examination of beliefs about knowledge (reviewed by Elby et al., 2016). However, it has recently been argued that a broader definition of epistemic cognition that does include affect, motivation and learning context may be more useful because the narrow focus misses important aspects of student behaviour (Chinn, Buckland, \& Samarapungavan, 2011). We concur with the latter view, reflecting our interest in how students respond to particular ideas in particular contexts and the interplay between ethics and epistemology. 


\section{Research aims and questions}

We have used the lens of proximal and distal views of science knowledge to investigate students' understandings of the need for judgment in producing, analyzing and presenting scientific data and the consequent ethical implications. The specific issue of data and the more general issue of critique of claims has been identified as an omission from many science curricula (Duschl, 2008; Ford, 2008; Roth, 2012) but one that is important to science education. It is, therefore, important to assess students' attitudes to these issues so that pedagogical strategies are developed from an evidence base. The teaching approach examined here was to problematize data interpretation through case studies of scientists facing difficult decisions on the generation, analysis and presentation of scientific data, including where the difficulties might be seen to arise because the scientists held a conceptual conviction that, in the face of conflicting data, resulted in a moral dilemma. There are particular issues around decisions to remove outlying data points that students find challenging because there is a fine line between acceptable data manipulation and that which is fraudulent. Pre-reading for the case studies covered cases of famous scientists whose decisions to include data, or not, were open to the interpretation that they may have behaved fraudulently. The cases included examples where data was challenging to collect and the experiments prone to technical difficulties and where scientists had prior commitments to particular theories. The need for the scientists to make decisions about which data should be included in the final analysis was therefore highlighted, introducing students to the more general issue of how scientific data is generated and validated (Roth, 2012). This context prompted students to consider and justify ethical judgments in science - both their own and those of professional scientists. Their responses to the case studies have been analysed to answer the following questions: 
1) To what extent do undergraduate science students recognise the need for ethical judgements in data analysis and how does this change after a case study on this issue?

2) What factors influence students' ethical judgments in proximal and distal domains?

We have taken a sociocultural approach to the analysis of student views, drawing on a body of research suggesting that students should be given opportunities to understand the process of science and to develop their own thinking about science (Clough, 2006; Duschl, 2008; Matthews, 2012; Rudolph, 2014), rather than adopting a prescriptive approach that privileges particular views. Such approaches lend themselves to a situated analysis of students' ethical and epistemological development (Sandoval, 2014; Sandoval, 2005; Sinatra \& Chinn, 2012) in which both proximal and distal views of science may emerge. It is important to include reflections of students in studies of this kind because reflections may include justifications for behaviours that may not be evident from direct observation of practice (Sandoval, 2014) and because the act of reflecting may prompt deeper engagement and epistemological development (Bendixen \& Rule, 2004; Sinatra \& Chinn, 2012). Thus, our approach has been to provide students with stimulus material on the ethical implications of data interpretation and then to analyse their reflective responses.

\section{Methods}

\section{Context and participants}

Participants were enrolled in a first year cross-disciplinary course on the nature of science, which has been described previously (Howitt \& Wilson, 2014). The course is taught as a series of case studies on different issues of science and encourages students to develop and discuss their own opinions. It has been taught at a research-intensive university for three years with 30-45 students 
each year, $60 \%$ of whom were female. The majority of enrolled students were in their first year of university study and were undertaking a Bachelor of Science or one of its higher-entry score variants that focus on research experiences. Most students were enrolled in three other, conventional science courses, with a minority undertaking arts or law courses in addition to science. Students enrolling in the course represented a reasonable cross section of the science disciplines including psychology and earth sciences as well as maths, physics, chemistry and biology.

At the start of the course, students were asked if they were willing to allow their written submissions to be used as data in a research project examining how students learn about scientific research processes. Permission was given via forms approved under the Human Ethics Review process at the institution. The written reflections on the relevant case study and the final integrative reflection of the 101 students who gave permission (92\% of all students in the course) have been used in the analysis.

As mentioned above, the case study on data manipulation included readings on a series of historical instances of possible data manipulation or fraud. One reading described how the Nobel prize-winning physicist Robert Millikan initially published all his data, including what the scientific community at the time deemed as evidence of inadequate scientific skill (Waller, 2002, Chapter 2). His scientific notebooks show that Millikan excluded results that were not consistent with his findings in later publications - sometimes with a rationale based on the experimental conditions, but sometimes with no stated reason. This case study gave the opportunity for students to discuss and reflect on the role of gut feeling, and the ethics of suppressing data in response to earlier criticisms of inadequate professional competence. 
Another reading described how another Nobel prize-winning physicist, Arthur Eddington, reported only those results that supported Einstein's theory of general relativity when he set out on an observation of a solar eclipse through which he intended to prove this theory (Waller, 2002, Chapter 3). This case study gave students the opportunity to discuss and reflect on the complex role of conviction and belief in science and scientific progress. It raised the question of whether someone who was one of the only people in the world at the time to understand Einstein's work (and so might be capable of judging its scientific and logical merits) might be tempted to construct the strongest possible argument for its acceptance.

The final reading concerned the famous twin studies undertaken by psychologist Cyril Burt, in which he is suspected to have invented not just data but both participants and co-researchers (Wade, 1976). In this case, the inadequacy of Burt's ethics with respect to data might be clearer than in the cases of Millikan and Eddington, but the opportunities to discuss wider and more long-term social consequences were richer. Classroom activities also introduced examples of demonstrably fraudulent scientists.

Students were encouraged to consider the level of ambiguity in the data in the different cases, and to postulate reasons why a scientist might consciously or unconsciously misrepresent their results, both in terms of conceptual convictions and sociocultural factors such as religious beliefs, or the seeking of personal gain/status.

\section{Data collection and analysis}

Formative and summative assessment activities during the course provided rich qualitative data that allowed us to explore variation in the ways in which students responded to questionable manipulation and presentation of scientific data. After each case study, students were provided 
with a prompt question for their reflection that left open whether they discussed their own behaviour or that of professional scientists. Students also completed a final reflection at the end of the course in which they were asked to consider how the course had changed their views of science. In each reflection, students were asked to write about their views and to justify their opinions. By encouraging such epistemic reflection (Sinatra \& Chinn, 2012), we hoped to gain information on the beliefs they used to make sense of science and their epistemological goals and discourse (Sandoval, 2014). We thus not only had a snapshot of the range of views and responses of students enrolled in the course; we also had evidence of if and how their views changed over the semester, and their own post facto reflections on those changes.

All reflections were de-identified and entered into NVivo to facilitate analysis of data and identification of material relevant to particular themes. Qualitative analysis of the reflections used a constant comparative approach (Strauss \& Corbin, 2008) to identify emergent themes relating to students' perspectives on their learning and their understandings of the nature and practice of science. Our analysis was informed by the techniques of phenomenography (Marton $\&$ Booth, 1997), which focuses on range and variation in understandings or conceptions (rather than looking for the most commonly-held conceptions) and is particularly effective in identifying hierarchies of expanding sophistication or nuance.

The analysis proceeded in several stages. Initial open coding was based on searches of the reflections in NVivo against key words, for example, fraud, data manipulation, practical class, to identify relevant subsections of each text. Using the paragraphs extracted in this way, the first author developed codes based on common themes raised in the reflections, and within those, identified whether proximal or distal science was addressed. Initial codes and sub-categories were descriptive and wide-ranging, for example, scientists as human beings (eg, motivation, bias, 
empathy, peer pressure) and experimental data (eg, objective, manipulation, fraud, publication, need for interpretation, scientific method). During this process, it became evident that students exhibited a range of qualitatively different views relating to both proximal and distal conceptions of science. These appeared to represent different degrees of sophistication in their awareness of nuance around the need for scientists to make and validate judgments on data. Many students also commented on the ways in which they became aware of more possibilities, demonstrating transitions to positions of greater sophistication. This led to a phase of more conceptual coding, with the focus on variation in the recognition of nuance. (Here, consistent with phenomenographic approaches, sophisticated or nuanced does not refer to a more or less "correct" response. Rather, a less sophisticated understanding is one that recognizes only a small number of factors and/or possibilities, while a more sophisticated understanding is one that recognizes more factors and possibilities.)

The second phase of the analysis thus structured the data along two conceptual dimensions: proximal/distal, and awareness of nuance. These codes were then tested by both authors reading complete reflections to ensure that the codes were consistent with students' arguments, refining, elaborating and changing the coding as necessary. As these structures were further refined, it became evident that they could be mapped onto the epistemological positions identified by Perry (1970) resulting in an adjustment of categories that formalized this similarity. This was consistent with our aim of understanding students' responses to the ethical implications of data analysis and provided a theoretical framework with which to examine change. The codes from this stage of the analysis and how they mapped to Perry's positions are shown in Table 1. Thus, Perry's positions became our primary categorisation, with proximal and distal responses seen 
within these, and we began to focus more on transitions between these categories, and to look for what appeared to trigger them.

\section{Insert Table 1 about here}

The final phase of analysis involved several reliability checks to confirm coding and classifications. Throughout all three phases, clarification of the coding structure followed an iterative process as both authors read and discussed the reflections and the codes, leading to agreement on the final categories. We also actively searched for reflections that showed transitions between the modes and critically examined these to ensure we had not missed important phases. In the final iteration, representative quotes were considered in context of the entire reflection to ensure that participants' views were accurately represented and that the quotes were illustrative of the mode. Reliability was also enhanced by triangulating data obtained from reflections with questions posted to the course discussion forum, the initial survey completed by students and notes from class discussions. The questions, in particular, highlighted the difficulties that students had with making judgments and in accepting the fallibility of scientists, confirming the focus of our analysis on transitions and ethical development.

\section{Evidence for changing epistemological and ethical understandings of scientific judgment}

The questions posted to the course discussion forum, class discussions and written reflections showed students were thinking seriously about the representation and manipulation of data and the difference between data and published results, often apparently for the first time. Some students recognized that scientists are sometimes in situations where they must make professional judgments about what constitutes publishable data. Some recognized a range of factors that might lead to scientists subconsciously excluding some data as invalid, such as bias, 
culture, religion and so on. Students also discussed pressures and personal drives that might lead to the conscious manipulation of data.

We observed that a consideration of the ethical aspects of data selection and presentation prompted many students to recognise the contestability of scientific claims and the need for judgment. Within the written reflections, a range of levels of sophistication regarding these positions was evident. As discussed above, these levels mapped closely to the various levels of intellectual and ethical development described by Perry (1970) and one of the most striking aspects of the data was the ways in which transitions between these levels were evident. In the following, we show that many students started the course at the least sophisticated, dualist level of Perry's scheme (Figure 1). We then provide evidence for transitions to more sophisticated levels, as students recognise uncertainty and eventually become able to make judgments based on evidence (Figure 1 and Table 1). We suggest that lower levels of sophistication tend to be coupled with students' self-perceptions as very different to practising scientists, and that increasingly sophisticated positions with regards to data manipulation are coupled with an increasingly strong identification between students and scientists.

\section{Initial views of science are largely unexamined}

Our first research question was, to what extent do undergraduate science students recognise the need for ethical judgements in data analysis and how does this change in response to the case study? In their final reflections, students discussed changes in their views during the semester, with many identifying their initial views as unsatisfactory for various reasons. A strong theme that emerged from these reflections was that most students had not previously considered what it means to be a scientist and to do science. The role of science student had been accepted without 
question and for many this included a largely extrinsic motivation to gain marks, even when students were also interested in science for its own sake. This resulted in the view that it was acceptable for students to alter results during laboratory work, as Jonathan explains.

We knew the answers we were meant to be getting, obviously there was something wrong with the equipment we were using or our technique - it wasn't exactly state of the art. I'd never really thought of this as unethical, I knew we weren't meant to do it, but then again it wasn't like we were performing ground breaking research, it seemed to me that the most important thing was to get what I knew, without question, were the right answers. (Jonathan)

Comments such as this one indicate that students are completely focused on proximal science and do not see laboratory work as professional practice or consider the implications for their development as scientists. Similar attitudes were observed in previous studies of chemistry students' attitudes towards laboratory work (Del Carlo \& Bodner, 2004; Vhurumuku et al., 2006). A consequence of this attitude is that students do not see the need for professional judgment. Since they perceive that a right answer exists, the task of a scientist is to uncover this answer. This reflects an inappropriate extrapolation of a proximal view based on the student's experience of learning science to the nature of professional science. The two quotes below illustrate the proximal and distal expressions of this view.

I really liked studying science because I believed it was objective and there was always a 'right' answer. (Sophie)

The definition of scientific method which I have held for most of my thinking life was as a process of discovery, analogous to the careful cleaning of a painting to reveal the masterpiece underneath. I considered scientific method to be a mode for the revelation of 'the true nature of things'. (Hannah)

On the surface, this latter description of science might seem quite appealing, and might be shared by some scientists, as it allows for initial findings to be over-turned or replaced by subsequent investigations. However, it represents an epistemological stance in which scientific knowledge is 
pre-existing truth, and fails to capture the sense that knowledge is created, not merely

discovered, through scientific work.

The scientific method was widely seen as a set of rules that scientists follow, again leading to a passive view of what scientists do.

I had a very idealised view of how both scientist and science actually worked. I believed that science followed the very well known and linear path known as the Scientific Method. (Daniel)

I also believed this [diagram of the steps of the scientific method] to be the one true scientific method which all scientists adhered to. (Mark)

Mark continued the discussion of his initial views with this comment on the class response:

I was not alone in missing ethics out when asked to think of the qualities of a good scientist. (Mark)

It is evident from these and similar quotes that many students had not previously considered that science might involve professional judgment; data from a pre-course survey, which had asked students questions aimed at probing their preconceptions about the nature of science, suggested that this was the case for the majority. Most students had unquestioningly adopted a somewhat idealized view of science, in which scientists were seen as 'seekers of truth', uncovering nature's secrets through the application of a defined and unwavering procedure of scientific method. Thus, both proximal and distal views excluded any need for judgment because the objectivity and rules of scientific method were seen as allowing no scope for intervention.

Final views of ethical judgments in science evolve for many students

Throughout the course, many students became more aware of the ethical dimension of data analysis but a wide range of views was observed. Most students themselves noted significant 
changes in their views of data manipulation and presentation during the course. Almost all reflections included discussion of distal views of science as students wrote about their responses to the case studies. Not all reflected on their own practice but many also discussed proximal views of science, with some attempting to integrate the two. This led to a much more diverse range of views than had been held initially (at least as deduced from students' retrospective reflections and supported by the pre-course survey). A set of hierarchical categories that covered the range of perceptions evident in the participants was developed. Four categories, based on the four core positions defined by Perry (1970) were identified (Figure 1). A feature of these positions is that they are qualitatively different, and movement between them requires significant conceptual changes, which were sometimes evident in the students' reflections. All categories covered both proximal and distal views, although not all individual students wrote about both. Table 1 summarizes how each mode was expressed in relation to proximal and distal conceptions of science and scientific practice. The following sections explore these expressions in more detail.

\section{Mode 1: dualism}

Students who appeared to be in this category at the end of the course held the belief that science is completely objective and there is no need to use judgment in the use and presentation of data. Most had not changed their views throughout the course. Such students labelled all selective data use as fraud and in the most extreme position, failed to recognize that the behaviour of scientists can be influenced by their expectations and backgrounds. The quotes below are typical in their expression of absolute values and their characterization of science as being about 'facts' or 'truth'. 
I feel that any scientist ever found to have indulged in such behaviour should be tossed out of science (similar to a crooked cop), and I view those who partake in these activities with disgust. I realised I may hold a rather extreme viewpoint here, but I feel that falsifying or creating data simply goes against everything science stands for: truth; an unbiased verifiable source of information; promoting understanding about our world; advancing the human race. (Brendan)

My views of fraud and the manipulation of data have not changed much over the course of the semester. I still believe that scientists should be completely honest, because science is a field that is concerned with facts. (Ella)

The epistemological stance held by Brendan and Ella clearly allows no room for ambiguity, doubt, or moral ambivalence in science.

Some students in this category could accept the humanity of scientists and that they might be susceptible to non-scientific pressures or motivations. However, while these students might understand why this occurs, it did not alter their perception of the objectivity of science. Instead, they felt that some scientists do not live up to their ideal. While most students in this category focused on distal views of science (perhaps because their less nuanced understanding does not leave room for the adoption of multiple positions) some were able to identify with scientists, at least to some extent, as Lucy describes understanding the scientists' data manipulation and her use of 'we' in this reflection:

The in-class discussions helped me understand a little of what motivates a scientist to commit scientific fraud pressure to be correct was the main one, I thought, with personal beliefs close behind. As I discussed earlier, it's essentially impossible for humans to be objective. I think that often we pick a theory or idea that we like, or consider 'beautiful', and we will defend that theory until we are conclusively proven wrong. I can understand why scientists do this, but I do not think it's particularly 'good' science, since science almost by definition is very rational and logical. (Lucy) 
Lucy has not realized the importance of defending theories as one of the drivers for scientific progress, as it ensures that those challenges that successfully overturn theories are robust and lead to better theories taking their place. The humanity that leads to bias and preference are thus seen wholly as flaws, rather than as elements that, handled well, make positive contributions to science. Matthew shows a similar stance:

After three hours of listening to people state their opinions on the matter, I still can't say my view has changed at all. What made me stick to my opinion was that the pressure that society places on scientist does not excuse scientists for fraudulent behaviour and manipulated data. If they want to be a "good scientist" they should aim to prove, disprove or make a discovery that follows the scientific method so it can be replicated and avoids error and/or extremely negative consequences. (Matthew)

However, here we see some evidence of a potential softening of this apparently black-and-white vision of good science. The presence of the word 'extremely' in the final phrase suggests that, perhaps, this student might consider imperfect scientific method to be acceptable if there were little or no negative consequences. A focus on the consequences of an action does appear to lead students to a greater awareness of complexity, prompting the beginnings of a transition to mode 2. In the excerpt below, Rosie makes a judgment based on the consequences of actions that she labels as fraud but she considers only extreme positions.

It seems to me that fraud isn't such a bad thing at low levels, as it is usually only to remove inconsistencies which are relatively minor in regards to the rest of the results from the experiment. However major fraud, such as manufacturing results, I would regard as being much more serious. Also fraud in regards to medical science, or other fields with a say over human living should be strictly forbidden so as to prevent the unnecessary loss of life. (Rosie) 
Although her stance is still based on the certainty of right and wrong, she does recognise that different responses might be valid for different types of 'fraud', paving the way for the transition to mode 2 .

\section{Transitions to Mode 2: multiplicity}

If students persist in holding mode 1 views, they will be unable to fully develop the skills needed to identify where judgment needs to be exercised and to make or evaluate those judgments. However, some students showed evidence of moving beyond the dualist mode to mode 2 of Perry's scheme. In the context of this course, mode 2 covers students who are struggling with the issues raised and are confused about where they stand. For those students where a transition was evident, that transition lay in their acceptance that science is not as objective as they had previously thought. However, in this mode, they have not yet realized that there might be a sound basis on which to make judgments. Transition to this level is thus characterised by confusion and frustration at the loss of certainty.

Both students quoted below accept that some manipulation of data might be constructive but still feel uncomfortable with it, labelling it as fraud. There is a perception that there must be a line between what is and is not acceptable but they cannot see where this line can be drawn or how it can be justified. This was seen largely in the context of professional science although many students recognized that the issue has implications for their own development as scientists, as shown by both quotes below.

Would I even be useful as a scientist if I didn't make my numbers neater? Would people take my work seriously? Millikan found that honesty held his work back, that there was too much opposition for him to continue his work under that kind of negativity. So what is more right, to be honest and have no one listen to you, or to 'adjust' data so that your work might be useful? I am so unsure about myself now. I don't know where I stand. I'm really 
uncomfortable with the lack of clarity that I have in regard to the place of fraud and data manipulation in science, but I hope that as I continue to learn and grow as a scientist I will find that my thoughts and beliefs become clearer. (Merryn)

Merryn has picked up on a really important reason to present data as more tidy than it might, perhaps, be in the raw, but does not yet have the capacity to accept that there is no hard and fast rule that gives the right answer in deciding what to do. She still wants one decision - to tidy up and be heard or to be honest and ignored - to be the right one. Alicia, on the other hand, recognizes that there may not be a clearly defined answer:

This definitely isn't an issue with a clearly defined answer, or at least not one I can see. The more I write this, the more my head is going round in circles - I can see arguments for both sides. I've come to realise that the problem of data manipulation and fraud is a much more complicated one than I previously thought. Whereas before I was wholly against it on principle (with the exception of high-school fraud), without having ever put much thought into the situation. Now, I found myself balancing some really significant scientific discoveries, which may not have occurred, or would have occurred much later without fraud, with the slow corruption of science and scientific methodology which can be seen right from the lowest levels of science with my own need to manipulate data to fit in with what I saw as 'right answers,' rather than questioning where my own answers had come from, which could potentially lead to even more significant discoveries. (Alicia)

Here, Alicia connects distal and proximal views, but in a way that perhaps misses a significant underlying difference. In her proximal experience, data manipulation occurs in order to achieve an externally given answer, so no judgment is needed about the answer itself. Distal manipulation occurs because of the absence of known answers, leaving room for competing theories, with one being believed in or subscribed to by the (fraudulent) scientist.

\section{Transitions to Mode 3: contextual relativism}


Both of the examples above seem to treat fraud/manipulation as the result of conscious decisions to deliberately deceive. Transition to the next mode, contextual relativism, involves an epistemological shift. Students in this category exhibit a more sophisticated view of science, which is expressed as an understanding of the complexity of science and a resulting need to be more sceptical about published results. They have come to accept that scientists do manipulate data for various reasons and that not all such manipulation is fraudulent, indicating that they have moved beyond a procedural view of scientific method as an unvarying set of rules. There is some recognition of the subjective aspects involved in doing scientific research and that scientists are individuals and therefore might not all make the same judgments in the same situation. One consequence of this is that they recognise that judgment also needs to be shown in the interpretation of published results because alternative interpretations of what is presented might be possible. These students are coming to understand the evidence-based nature of science, a transformation evident in the following excerpts:

We've discussed the difficulty in being an apparently 'perfect' scientist and I've realised that it is more difficult than one may think, simply because of the difficulty in scientific work. I've realised that the issue of being a 'perfect scientist' is entwined into something more than simply performing an experiment correctly. (Eliza)

Bias and the pressure placed on scientist can lead to fraud and errors. And as a result I have found myself questioning more things I considered to be 'facts 'and looking for alternative causes or explanations. (Nicholas)

Initially I felt that the deletion of data was fraudulent in any given circumstance, but class discussions made me realise how context is crucial in determining whether it is purposely deceptive or 'good science'. (Olivia)

Students who have transitioned to this category apply their new understanding of professional science to their own practice of science. They see that laboratory exercises undertaken during their degree are preparing them to practice as scientists and they reflect on the need to try to 
understand results, rather than simply looking for a right answer. Both proximal and distal views of science become more sophisticated as students realize that developing the ability to make judgments about data is an important part of their learning. They are coming to see science as a quest for knowledge, rather than as a collection of facts to be learned; in fact developing the ability to critique knowledge claims. For some students, this resulted in a significant change in attitude towards the laboratory components of their courses and many become critical of their own prior manipulation of laboratory results.

Errors happen and unexplained results occur, this is half the fun! It has emerged this week that the important thing is to be able to explain or at least reflect on what went wrong, or rather what is scientifically occurring to give such results. I have realized that my practice of simply forging results to get out of labs early is selling myself student short of a true depth of scientific understanding that could lead to great discoveries in the future. (Lachlan)

It is interesting to note here Lachlan's recognition of the importance of reflecting on, rather than always necessarily having an explanation for, what went wrong. A related observation was made by Celia, who reflects on her biology tutor telling her to discard a result that is too low because it is most likely due to a technical problem. She is able to use this proximal experience to develop a more sophisticated distal view as she considers the role of expertise and community feedback:

Data interpretation is not always straightforward but sometimes scientists will need to make judgments and given that they possess a great deal of understanding of their field and experience, I think they are qualified to make such judgments. This is not to say that scientists will not sometimes make the wrong judgment. However, through the scientific process these wrong judgments can be discovered, which is part of what makes science work as well as it does. (Celia)

Both Lachlan and Celia have recognised that anomalous results are an occasion for judgment and that different scientists (or students) might make different decisions in such situations. 


\section{Transitions to Mode 4: Commitment}

The most sophisticated responses to data manipulation exhibited an understanding of the interaction between science, education and society; students with such responses recognized that attitudes and values may be socially determined. Instead of simply blaming individuals for unethical behaviour, these students recognize that both students and scientists respond to external pressures and that this may impact on the way they undertake scientific activity. Thus in the context of learning about science, Perry's fourth mode of thinking is characterized by the ability to not only recognize that social systems place both scientists and students under pressure to perform, but also to critique those systems and make judgments about them.

Transitions to mode 4 were evident in comments such as Patrick's reflection on his previously inadequate view of science.

I would never have thought that there would be anything remotely interesting about the concept of science - don't get me wrong studying science is interesting, but really, everyone knows what science is right? We've all studied a certain amount of the subject in high school at least. But this has gotten me thinking - what do we learn about science in high school? By the number of people who fake their lab results in high school science classes, I don't think we learn what the essence of science is, how science works, and most importantly why we do science. (Patrick)

Patrick has realized that his education has not provided him with a useful understanding of the nature of science so has become critical of the system that has led him into the belief that it is acceptable to manipulate laboratory results. Similarly, both Joe and Hannah are aware of the different environments of proximal and distal science and have suggestions for the education system, as shown in these excerpts. 
The most important thing in the final exam is to get as many answers right as possible, and less emphasis is put on learning from your mistakes- as the final exam marks the end of the semester, there is not generally a chance for this. I think professors (although I am sure many already do) should emphasise to their students that getting things wrong is often just as important as getting them right- anomalies in research can themselves lead to new discoveries. (Joe)

Reflecting on the role of creativity in science has been of particular interest to me this semester. I see a strong disparity between studying science and undertaking scientific research...... I think a creative approach to problem solving and data interpretation is key to good scientific method and as such I think the encouragement of creativity in students would go a long way to preparing science students to be scientists. (Hannah)

Other students criticized the culture of science for the pressures placed on scientists, recognizing that the level of data manipulation that occurs is to some extent determined by scientists' need to succeed in the competitive world of professional science. The following shows a student who is perhaps still undergoing the transition between mode 3 and mode 4 :

Is it all bad? I believe that some manipulation and presentation is purely simplification and has merit in that. Sometimes to focus on the important issues at hand tidying up results is logical and doesn't constitute fraud. Aberrations in data are inevitable and often insignificant, finding their cause in human or mechanical error. It's not always feasible to repeat experiments on account of a couple of unusual points. Perfect results are unobtainable but against a background of competition for recognition and financial aid there is an incredible amount of pressure to produce them. There should perhaps be more recognition of this difficulty and more understanding amongst scientists when all must deal with the same problems. (Zoe)

The use of words such as 'aberration' and 'error', and the reference to 'perfect results' (which even if unobtainable by implication are "out there" in some platonic form) suggest mode 3 thinking. However, the recognition that all scientists deal with such problems, and that mutual 
understanding of this would be better than striving for unattainable perfection, suggests the transition to mode 4 is under way.

Students transitioning to mode 4 show an appreciation of the complexity arising from the interactions between science and society and have developed their own views on what is and is not acceptable. While this might not be commitment in the sense used by Perry, it does show a domain-specific acquisition of values which students are using to make judgments.

Relationships between sophistication of understanding of scientific judgment and degree to which proximal and distal views are separated

Our second research question was what factors influence students' ethical judgments in proximal and distal domains? Our findings suggest that the two features (proximal/distal views and variation in sophistication of understanding of scientific judgment) that emerged in the students' reflections can be represented as two dimensions of variation, as shown in Figure 2. In this figure, the vertical axis represents variation in sophistication of understanding in relation to scientific judgment, and the horizontal axis represents the degree to which students' proximal and distal conceptions differ or coincide.

\section{Insert Figure 2 about here}

Initially, many students applied different ethical standards to proximal and distal science, clearly indicating that they saw them as separate enterprises. Although a small number of students applied the moral absolutist view to both student and professional science (represented by quadrant B), most expected higher standards of ethical behaviour from professional scientists than from themselves and their peers (a position represented by quadrant A). As noted earlier, 
this was largely due to their idealistic view of scientists as objective seekers of truth and their failure to consider their own learning in the context of what scientists actually do.

As students reconsidered their initial views, many recognised the uncertainty of science which allowed them to make ethical judgments using both a new understanding of professional science and a consideration of the science they do in the light of professional practice. This led to a range of opinions on the ethical standards expected for proximal and distal behaviours that fell into two broad classes; some students accepted the distinction between proximal and distal science and used the differences to justify different ethical standards while others more strongly identified with scientists and applied similar standards. Thus by the end of the course, some students held views corresponding to quadrants $\mathrm{C}$ and $\mathrm{D}$ in Figure 2. We explore these different positions in the following.

Responses corresponding to quadrant $\mathrm{C}$ in Figure 2 justified different proximal and distal ethical standards on the basis of two factors; the lack of authenticity of many laboratory exercises and the greater consequences of dishonesty for a professional scientist. Both Chris and Liam, quoted below, justify lower ethical standards for students than for scientists on the basis of these factors.

Most of the experiments that we are doing as students have already been done, and the results are well known and widely accepted as the "right" ones. This means that when we get something that doesn't fit the expected results we get a massive sense of being wrong which can be very hard to accept. The frustration of being wrong is what creates the temptation to tweak results. In contrast, professionals are crossing new boundaries and so there is no authority as to whether or not they are right or wrong. On top of that, since no one knows which direction a new experiment will go it is even more important that a professional does not mislead others down the wrong path. If they do, then a whole generation of scientists can be left digging in the wrong place. (Chris) 
They agreed that in class, changing results was excusable because students just want to be able to pass their courses or to not have to stay in for extra time during lab sessions. As opposed to big research projects where the results could make a real difference in the world. (Liam)

Erin has taken a slightly different approach to consequences, by considering the relative power and authority of students and famous scientists:

The political slant to Eddington's case is for me the difference between my ignoring of a point that is way off my expected range in chemistry, and the fraud that Eddington committed. The misuse of power and authority and the intent behind the action are the two things that contribute to the separation. (Erin)

Typical student laboratory activities do not have the uncertainty that characterises professional science (Chinn \& Malhotra, 2002; Hofstein \& Lunetta, 2004) but these students were now able to identify this as a significant difference from professional science and use it to justify lower ethical standards.

Responses corresponding to quadrant D evidence a merging of proximal and distal views as students begin to identify more strongly with scientists. These students maintained a level of idealism as they became more critical of themselves for failing to live up to the standards expected for scientists. They saw laboratory work as a preparation for professional practice and therefore they should be practising professional behaviour.

We were given several case studies of scientific fraud - I even stood aghast with some of them. I was astonished to see what it took some people to reach a certain goal. Even though I was aware of this issue before it was presented to us in SUtM, I had never really related it to my life or myself previously. As a good science student, in several occasions, I have manipulated the data that I got from my laboratory practicals. I remember in a discussion session it was mentioned that there is no difference between scientists and us, in terms of being fraudulent with our experimental results. After a little bit of pondering, I realised that this was indeed true. (Alex) 
Alex notes that this was the first time he had considered scientists in relation to his own behaviour. It is this aspect that is critical here, because he is explicitly comparing and critiquing proximal and distal views and experiences. A less idealistic approach that is still based on identification with scientists was the recognition of similar motivations for behaviour that may be considered unethical. While in itself the above excerpt might be interpreted as simply a shift from quadrant A of Figure 2 to quadrant B, much of the rest of Alex's reflection reveals he has also developed a substantially more sophisticated understanding of scientific judgements, as for example where he reflects on how science may at least in the long term be self-correcting:

Quite often scientists are swept in a current of ideas that leads them astray to the actual truth. However, these errors are corrected by the scientific community itself, which is one of science's strengths. Sometimes corrections may take years, decades, or even centuries (such as the Copernican revolution). An improved understanding of a particular theory may result from innovative technology or changing perspectives. (Alex)

Alex himself describes how he used to have a much more fact-based understanding of science, and hence it seems from his reflections that by the end of the course he has moved from a position represented by quadrant $\mathrm{A}$ to one represented by quadrant $\mathrm{D}$ in Figure 2.

Similarly, while Jess does not make a judgment about scientists' actions in the excerpt below, she accepts the range of motivations that contribute to data manipulation, seeing scientists as imperfect human beings, like herself. Implied in this is an acceptance of science as a human activity, rather than a completely objective pursuit. Again, it appears that this is not something she had previously considered and is indicative of a merging of proximal and distal views of science.

Now that I think about it, how different am I from Millikan and Eddington? They probably wanted fame, recognition, convenience and to prove their hypothesis correct. I wanted good grades, getting out of class on time, and to have convenient and explainable data to write my preconceived conclusion on. (Jess) 
Thus our data suggest that reflection on these case studies may either strengthen a sense of difference through an awareness of asymmetries in terms of power and consequences, or reduce it through the recognition that scientists are fallible and potentially flawed human beings just like the students themselves.

\section{Discussion}

We set out to examine students' responses to issues of ethical judgment in scientific research by providing case studies where famous scientists made decisions to use data selectively. These decisions were justified by the difficulties of data collection as well as the scientists' desire to have an impact. As students discussed and reflected on the case studies, it became clear that these issues challenged students' epistemological and ethical stances at a fundamental level. Many students entered the course with an idealised perception of science as completely objective with little or no need for judgment. They had little understanding of the ways in which scientists use evidence to come to conclusions or of the tentative nature of their conclusions, resulting in a failure to recognise the ethical implications of data interpretation. Faced with examples of famous scientists using their judgment where the evidence was ambiguous and there was no clear answer, many students found their initial understanding of science challenged. For some students, this led to profound changes in how they view science and what scientists do.

Our results illustrate considerable variation in students' views of the ethics of scientific research, both in relation to professional science (distal view) and the science they experience as part of their degree (proximal view). We found that students' developing ability to recognise, understand and perhaps make ethical judgments relies upon changing conceptions of scientific knowledge that recognise uncertainty and the role of evidence. The categories we have identified 
form a hierarchical sequence, ranging from a moral absolutism in which science is seen as truth and scientists deal with unambiguous facts to the ability to recognize the complexity of scientific research and its interaction with society, with the concomitant need to exhibit judgment in the analysis and interpretation of data. While our focus was on developing professional judgment in the use of data, the student responses clearly exemplify the intellectual and ethical positions first developed by Perry (1970).

It is evident that the students in our sample are engaging with the issue of data interpretation and observing change within themselves, with a number reflecting on their earlier and less sophisticated (and often unquestioned) views of science. We clearly see students struggling with the first two transitions that form part of the Perry scheme (Figure 1), firstly in recognizing that science is more than a collection of incontestable facts and secondly in understanding the evidence-based nature of scientific conclusions. The third transition, which entails commitment to a set of values, is less evident although some students do make value-laden judgments about the culture of science and their own education. We also observed some students who did not change their views, maintaining a largely dualistic outlook. Further investigation is required to understand why there was a much greater impact on some students than others.

There is likely to be a complex relationship between a student's intellectual development, their proximal and distal views of science and their experience of science teaching (Hogan, 2000). Although we set out to examine students' developing awareness of the role of ethical decisionmaking with respect to data manipulation and presentation, it became evident that this development is dependent on, and coupled to, the development of a more complex view of knowledge than that it is right or wrong. As illustrated in the preceding sections, students become aware of both more factors and increasing possibilities, and this opens up the space in 
which they are can see that judgments need to be made, as well as ultimately furnishing the bases for such judgments. This development is essential to gaining a grasp of practice (Ford, 2008; Ford, 2015), which encompasses the construction and critique of knowledge. In contrast to the context-dependent judgments and actions one would expect from a student with such a grasp of practice, students with a dualistic mindset are dependent on rules defining right and wrong and will have difficulty recognizing the need for judgment in any context.

It is striking that we see almost the full range of Perry's positions among first year students, in contrast to other studies of epistemological development that show change occurring over a period of years (reviewed in Hofer \& Pintrich, 1997). One open question relating to epistemological development is the extent to which the stages do, in fact, represent a developmental process. Observations that different positions occur in different contexts and in students of different ages and that students can stall or go backward have been taken as evidence against developmental stages. Instead, it has been argued that students have a range of epistemic resources and deploy them according to how useful they are in particular contexts (Elby et al., 2016; Hammer \& Elby, 2002). Our observation of all stages in response to a relatively shortterm intervention (a two week case study combined with ongoing reflection and revisiting throughout a single semester course) supports this view as an accelerated developmental pathway seems less likely than a context-dependent recognition of greater nuance. Coupling the Perry scheme with the notion of distinct proximal and distal views of science and scientific practice emphasises our sense that it is not a scheme through which students progress, as they are capable of simultaneously holding more and less sophisticated positions in relation to their own behaviour and that of others. The greater sophistication that we observed as the course progressed may have resulted from students' recognising that science was an appropriate context 
for the more sophisticated epistemology they adopted in other domains; our results clearly support a changing conception of science, in which students explicitly link proximal and distal views.

This is consistent with increasing evidence supporting the domain-specific nature of epistemic cognition (Chinn et al., 2011; Muis, Bendixen, \& Haerle, 2006; Sinatra \& Chinn, 2012) and confirms previous suggestions that proximal and distal science may be considered different domains where different epistemologies are applied (Hogan, 2000; Sandoval, 2005). In an argument for a broader conception of epistemic cognition, (Chinn et al., 2011) included epistemic values, aims and virtues, which recognise the importance of affect and motivation. These were all seen to be context-dependent and largely defined by the learning environment. For example, epistemic virtues - dispositions that promote epistemic development - are perhaps are not supported by the way many science courses are taught but could be fostered by a more open and questioning environment. Models for the development of epistemic cognition (Bendixen \& Rule, 2004; Muis et al., 2006) also include the learning environment, or epistemic climate, as a modulator of the epistemic approach students adopt. Such models view epistemic development as enculturation into ways of thinking that are influenced by culture, academic environment and the instructional context.

Acceptance of the argument for context-dependence raises questions about what prompts the adaptation of epistemological resources from one domain to another. One important factor in the course studied here was the recognition that science is a human (and community) activity, as our students developed increasingly sophisticated views in parallel with increased empathy or identification with scientists. Similarities between the epistemic cognition and conceptual change literatures have been noted (Sinatra \& Chinn, 2012) so our results would suggest that one of the 
most significant conceptual changes needed to develop a more sophisticated epistemology in science learning is for students to see scientists as fallible human beings doing the best they can in a competitive environment. This is supported by a recent study comparing students' responses to conflicts in history and biology (Thomm, Barzilai, \& Bromme, 2017). Explanations for the biology conflict were more likely to be focussed on the topic and how it had been addressed whereas those for the history conflict were also related to the researcher's background and motivations. It was suggested that this was because history was perceived as more subjective and therefore more open to human influence. The challenge is, therefore, to convince students to make the conceptual leap to a more comprehensive and humanist view of science by overcoming deeply-held proximal views of science as fact.

One instance where we do see transferability of epistemological and ethical values, is the inappropriate extrapolation from proximal to distal science. Such extrapolation of the learning experience to professional behaviour has been observed in other disciplines and can hinder the development of a professional identity (Reid, Dahlgren, Petocz, \& Dahlgren, 2008). We have provided evidence that the same thing occurs in science, with students who maintain a dualistic proximal view of data interpretation exhibiting a limited distal view that excludes the need for judgment. This is evident in the responses to anomalous data. Our students, like those in other studies (Del Carlo \& Bodner, 2004; Vhurumuku et al., 2006), mostly thought it acceptable to alter their own results because they were not doing 'real' science. In a discussion of the lack of authenticity of many classroom science activities, Chinn and Malhotra (2002) noted that the rational response to anomalous data is to reject it for exactly the reasons these students give. We showed that as the course progressed, many students moved from an unquestioned acceptance of 
this view to a point where they could justify their different expectations in terms of the differences between their lab experience and professional science. However, this position still fails to address anomalous data in the context of genuine discovery; for scientists, an unexpected result might be an indication of a new phenomenon, but equally, it could arise for many other reasons. Some students, however, continued to see all data as 'fact' and labelled all rejection of anomalous data by scientists as unethical, regardless of context. Another study has shown that unconsidered rejection of anomalous data occurs well into postgraduate training (Samarapungavan et al., 2006), suggesting that this view is resistant to change, perhaps because students remain tied to their proximal conceptions. The impact of proximal views on perceptions of science highlights the need for the integration of a more realistic approach to data interpretation into science curricula that better reflects the practices of science (Ford, 2008; Roth, 2012). Examples such as this one demonstrate the value of examining students' ideas and understandings that are situated in the learning environment as it allows an exploration of more nuanced and contextual factors (Bendixen \& Rule, 2004; Chinn et al., 2011; Elby et al., 2016; Kelly et al., 2012; Sandoval et al., 2016; Sinatra \& Chinn, 2012).

\section{Limitations}

Our study took a qualitative approach to identifying variation in student responses to questions of scientific ethics. We observed a wide range of responses but it was not possible to determine the frequency of the different responses within our sample. This was because our analysis was based on student reflections in which students could choose to discuss issues of importance to them. While most students did include data manipulation in their final reflection, some merely commented but did not explain their own views, while others included only proximal or only 
distal views. Additionally, although our sample of 101 students was quite large for a qualitative study and did represent the range of science disciplines, this group may not be representative of the entire student population. The course studied here was an elective and thus our sample was self-selected to some extent. Students choosing this course, which was presented as a multidisciplinary course on the nature of science, may have broader interests or a greater willingness to engage with such issues than those who chose not to do it. Further studies could sample a more representative population of students. We do not know whether the changes we observed are lasting and will persist in the face of different approaches to science teaching in students' other courses. This could be addressed by a longitudinal study tracking students' views over the course of their degree and complemented by classroom observations and interview to explore individual student responses.

\section{Conclusion and pedagogical implications}

It appears that many students do not recognise the ethical dimension of data interpretation in science because they have a naive view of science as totally objective. We have shown that substantial epistemological and ethical changes can occur when science students are encouraged to discuss and justify their own views and that the issue of use and abuse of data is a productive stimulus for change. As students compared their own laboratory work in other courses with historical examples of science, they were able to recognise different proximal and distal standards and consider implications for their own behaviour. This enabled them to make contextrelated ethical judgments about both scientists and themselves, supporting suggestions for the inclusion of historical case studies in the science curriculum (Allchin, Andersen, \& Nielsen, 2014; Clough, 2011). More sophisticated views tended to be accompanied by increasing identification of students with scientists, often leading to a merging of proximal and distal views 
of science. Interestingly, this was sometimes also coupled with criticisms of the education system that had led them to hold views they now recognised as unsatisfactory.

Our study contributes to calls to consider the epistemological implications of science teaching and learning activities (for example, Chinn \& Malhotra, 2002; Duschl, 2008; Ford, 2008;

Hofstein \& Lunetta, 2004; Roth, 2012), by providing evidence that students extrapolate proximal epistemologies derived from simple laboratory activities to professional science; clearly an unintended consequence. We have also shown that reflection on proximal and distal activities can have a significant impact on students' conceptions of science and provided support for the need to address both proximal and distal conceptions of science in scaffolding learning about the nature of science (Sandoval, 2005). We would go further and suggest that students' attention should be explicitly drawn to these two contexts; as our discussion of Figure 2 illustrates, when students make comparisons between themselves and scientists, they are able to identify contextual differences which justify different behaviours, leading to a more complex understanding of science. Learning critical thinking (in its broadest sense) in science is "existentially as well as intellectually challenging" (Nelson, 1999, p178) and science curricula need to provide opportunities for students to engage with complex and ambiguous issues in ways that encourage reflection and personal development. Students in the course studied here valued the opportunity to develop and discuss their own opinions but also found the approach challenging (Howitt \& Wilson, 2014), which are likely to be key factors in fostering a supportive epistemic climate and prompting change (Bendixen \& Rule, 2004; Chinn et al., 2011).

The preceding discussion suggests that curriculum reform might focus on problematization of existing teaching and learning activities coupled with reflection as a complementary strategy to the development of more authentic laboratory activities. The interpretation of data is an excellent 
issue to problematize in this way because not only is it crucial to the practice of science, but it also meets the criteria of dissonance and relevance identified as key factors in one model of epistemological change (Bendixen \& Rule, 2004). Data interpretation is relevant because students can relate it to their own laboratory experience but creates dissonance when they become aware of the issues professional scientists face and the differences between the proximal and distal contexts. This was evident in the surprise at scientists' behaviour many students expressed (Howitt \& Wilson, 2014) and prompts epistemic doubt, which is a pre-condition for change in this model. While necessary for change, relevance and dissonance were not seen as sufficient in the model, and this was confirmed by our finding that different students achieved different epistemic outcomes.

Equally importantly, our results suggest that a lack of awareness of the ethical dimension to decisions about data manipulation and presentation may actually serve as a barrier to development of a more sophisticated understanding of the nature of scientific data and knowledge; students simply fail to recognise that science is a domain where a more sophisticated epistemology is relevant. We might speculate that one of the reasons that students' conceptions of the nature of science are notoriously hard to change is that they encounter very few opportunities in their learning to explicitly explore such issues and confront ambiguity. We hope that other researchers and educators will develop approaches to teaching and learning that allow students to reflect on how ethical decision-making enters into scientific practice both in courses like the one studied here and in more conventional scientific coursework.

\section{References}

Allchin, D. (2003). Scientific myth-conceptions. Science Education, 87(3), 329-351. 
Allchin, D., Andersen, H. M., \& Nielsen, K. (2014). Complementary Approaches to Teaching Nature of Science: Integrating Student Inquiry, Historical Cases, and Contemporary Cases in Classroom Practice. Science Education, 98(3), 461-486.

Bendixen, L. D., \& Rule, D. C. (2004). An Integrative Approach to Personal Epistemology: A Guiding Model. Educational Psychologist, 39(1), 69-80.

Broad, W. J., \& Wade, N. (1982). Betrayers of the Truth. New York, NY: Simon and Schuster.

Chinn, C. A., \& Brewer, W. F. (1993). The Role of Anomalous Data in Knowledge Acquisition: A Theoretical Framework and Implications for Science Instruction. Review of Educational Research, 63(1), 1-49.

Chinn, C. A., Buckland, L. A., \& Samarapungavan, A. L. A. (2011). Expanding the Dimensions of Epistemic Cognition: Arguments From Philosophy and Psychology. Educational Psychologist, 46(3), 141-167.

Chinn, C. A., \& Malhotra, B. A. (2002). Epistemologically authentic inquiry in schools: A theoretical framework for evaluating inquiry tasks. Science Education, 86(2), 175-218.

Clough, M. (1997). Strategies and Activities for Initiating and Maintaining Pressure on Students' Naive Views Concerning the Nature of Science. Interchange, 28(2-3), 191-204.

Clough, M. (2006). Learners' Responses to the Demands of Conceptual Change: Considerations for Effective Nature of Science Instruction. Science \& Education, 15(5), 463-494.

Clough, M. (2011). The Story Behind the Science: Bringing Science and Scientists to Life in Post-Secondary Science Education. Science \& Education, 20(7), 701-717.

Del Carlo, D. I., \& Bodner, G. M. (2004). Students' perceptions of academic dishonesty in the chemistry classroom laboratory. Journal of Research in Science Teaching, 41(1), 47-64.

Deng, F., Chen, D.-T., Tsai, C.-C., \& Chai, C. S. (2011). Students' views of the nature of science: A critical review of research. Science Education, 95(6), 961-999.

Duschl, R. (2008). Science Education in Three-Part Harmony: Balancing Conceptual, Epistemic, and Social Learning Goals. Review of Research in Education, 32(1), 268-291.

Edmondson, K. M., \& Novak, J. D. (1993). The interplay of scientific epistemological views, learning strategies, and attitudes of college students. Journal of Research in Science Teaching, 30(6), 547-559.

Elby, A., \& Hammer, D. (2001). On the substance of a sophisticated epistemology. Science Education, 85(5), 554-567.

Elby, A., Macrander, C., \& Hammer, D. (2016). Epistemic cognition in science. In I. Bråten, J. Greene, and W. Sandoval (Eds). Handbook of epistemic cognition, 113-127. New York: Routledge.

Fanelli, D. (2009). How Many Scientists Fabricate and Falsify Research? A Systematic Review and Meta-Analysis of Survey Data. PLoS ONE 4(5): e5738.

Ford, M. (2008). Disciplinary authority and accountability in scientific practice and learning. Science Education, 92(3), 404-423.

Ford, M. J. (2015). Educational Implications of Choosing "Practice" to Describe Science in the Next Generation Science Standards. Science Education, 99(6), 1041-1048.

Gherardi, S. (2009). Practice? It's a Matter of Taste! Management Learning, 40(5), 535-550. Hammer, D., \& Elby, A. (2002). On the form of a personal epistemology. In B. Hofer \& P. R. Pintrich (Eds.), Personal epistemology: the psychology of beliefs about knowledge and knowing. Mahwah, NJ: Lawrence Erlbaum Associates. 
Handelsman, J., Ebert-May, D., Beichner, R., Bruns, P., Chang, A., DeHaan, R., Gentile, J., Lauffer, S., Stewart, J., Tilghman, S. M., \& Wood, W. B. (2004). Scientific Teaching. Science, 304(5670), 521-522.

Hodson, D. (1999). Going beyond cultural pluralism: Science education for sociopolitical action. Science Education, 83(6), 775-796.

Hofer, B. K., \& Pintrich, P. R. (1997). The Development of Epistemological Theories: Beliefs About Knowledge and Knowing and Their Relation to Learning. Review of Educational Research, 67(1), 88-140.

Hofstein, A., \& Lunetta, V. N. (2004). The laboratory in science education: Foundations for the twenty-first century. Science Education, 88(1), 28-54.

Hogan, K. (2000). Exploring a process view of students' knowledge about the nature of science. Science Education, 84(1), 51-70.

Howitt, S., \& Wilson, A. (2014). Developing, contesting and expressing opinions of science: encouraging the student voice. Higher Education Research \& Development, 34(3), 541553.

Ioannidis, J. P. A. (2012). Why Science Is Not Necessarily Self-Correcting. Perspectives on Psychological Science, 7(6), 645-654.

Kelly, G. J., McDonald, S., \& Wickman, P.-O. (2012). Science Learning and Epistemology. In J. B. Fraser \& K. Tobin \& J. C. McRobbie (Eds.), Second International Handbook of Science Education (pp. 281-291). Dordrecht: Springer Netherlands.

Latour, B., \& Woolgar, S. (1986). Laboratory Life: The Construction of Scientific Facts. Princeton, NJ: Princeton University Press.

Lederman, N. G. (2007). Nature of science: Past, present and future. In S.K. Abell \& N.G. Lederman (Eds.), Handbook of research on science education (pp. 831-880). Mahwah, NJ: Lawrence Erlbaum Associates.

Marton, F., \& Booth, S. (1997). Learning and Awareness. Mahwah, NJ: Lawrence Erlbaum.

Matthews, M. R. (2012). Changing the Focus: From Nature of Science (NOS) to Features of Science (FOS). In S. M. Khine (Ed.), Advances in Nature of Science Research: Concepts and Methodologies (pp. 3-26). Dordrecht: Springer Netherlands.

Merton, R. K. (1973). The sociology of science: theoretical and empirical investigations. Chicago, IL: University of Chicago Press.

Mitroff, I. (1974). The Subjective Side of Science. Amsterdam: Elsevier.

Moore, W. S. (2002). Understanding Learning in a Postmodern World: Reconsidering the Perry Scheme of Intellectual and Ethical Development. In B. Hofer \& P. Pintrich (Eds.), Personal epistemology: the psychology of beliefs about knowledge and knowing (pp. 1736). Mahwah, NJ: Lawrence Erlbaum Associates.

Muis, K. R., Bendixen, L. D., \& Haerle, F. C. (2006). Domain-Generality and DomainSpecificity in Personal Epistemology Research: Philosophical and Empirical Reflections in the Development of a Theoretical Framework. Educational Psychology Review, 18(1), 3-54.

Munafò, M. R., Nosek, B. A., Bishop, D. V. M., Button, K. S., Chambers, C. D., Percie du Sert, N., Simonsohn, U., Wagenmakers, E.-J., Ware, J. J., \& Ioannidis, J. P. A. (2017). A manifesto for reproducible science. Nature Human Behaviour, 1, 0021.

Nelson, C. E. (1999). On the Persistence of Unicorns: The Trade-Off between Content and Critical Thinking Revisited In B.A. Pescosolida \& R. Aminzade (Eds.), The Social 
Worlds of Higher Education. Handbook for Teaching in a New Century (pp. 168-184). Thousand Oaks, California: Pine Forge Press.

Perry, W. G. (1970). Forms of Intellectual and Ethical Development in the College Years - A Scheme. New York: Holt, Rinehart and Winston.

Reid, A., Dahlgren, L. O., Petocz, P., \& Dahlgren, M. A. (2008). Identity and engagement for professional formation. Studies in Higher Education, 33(6), 729-742.

Roth, W.-M. (2012). Data Generation in the Discovery Sciences-Learning from the Practices in an Advanced Research Laboratory. Research in Science Education, 43(4), 1617-1644.

Rudolph, J. L. (2014). Dewey's “Science as Method” a Century Later: Reviving Science Education for Civic Ends. American Educational Research Journal, 51(6), 1056-1083.

Samarapungavan, A., Westby, E. L., \& Bodner, G. M. (2006). Contextual epistemic development in science: A comparison of chemistry students and research chemists. Science Education, 90(3), 468-495.

Sandoval, W. (2014). Science Education's Need for a Theory of Epistemological Development. Science Education, 98(3), 383-387.

Sandoval, W. A. (2005). Understanding students' practical epistemologies and their influence on learning through inquiry. Science Education, 89(4), 634-656.

Sandoval, W. A., Greene, J. A., \& Bråten, I. (2016). Understanding and Promoting Thinking About Knowledge. Review of Research in Education, 40(1), 457-496.

Sinatra, G. M., \& Chinn, C. A. (2012). Thinking and reasoning in science: Promoting epistemic conceptual change. In K. Harris \& C. B. McCormick \& G. M. Sinatra \& J. Sweller (Eds.), Critical Theories and Models of Learning and Development Relevant to Learning and Teaching (Vol. 1, pp. 257-282). Washington DC: APA Publisher.

Smaldino, P. E., \& McElreath, R. (2016). The natural selection of bad science. Royal Society Open Science, 3:160384.

Steneck, N. H. (2011). The dilemma of the honest researcher. EMBO Reports, 12(8), 745-745.

Strauss, J., \& Corbin, P. (2008). Basics of qualitative research (3rd ed.). California: Sage Publications.

Thomm, E., Barzilai, S., \& Bromme, R. (2017). Why do experts disagree? The role of conflict topics and epistemic perspectives in conflict explanations. Learning and Instruction, 52(Supplement C), 15-26.

Vhurumuku, E., Holtman, L., Mikalsen, O., \& Kolsto, S. D. (2006). An investigation of Zimbabwe high school chemistry students' laboratory work-based images of the nature of science. Journal of Research in Science Teaching, 43(2), 127-149.

Wade, N. (1976). IQ and heredity: suspicion of fraud beclouds classic experiment'. Science, 194, 916-919.

Waller, J. (2002). Fabulous Science. New York: Oxford University Press. 
Table 1: Proximal and distal expressions of epistemological modes

\begin{tabular}{|c|l|l|}
\hline Mode & Distal view & Proximal view \\
\hline 1. Dualism & $\begin{array}{l}\text { Naïve view that science is } \\
\text { objective, data speaks for itself } \\
\text { so no manipulation is } \\
\text { acceptable }\end{array}$ & $\begin{array}{l}\text { Some students show empathy: } \\
\text { 'scientists as people', can } \\
\text { understand their motivations } \\
\text { and can relate to own } \\
\text { motivations but still see science } \\
\text { as completely objective }\end{array}$ \\
\hline 2. Multiplicity & $\begin{array}{l}\text { Naïve view of science } \\
\text { questioned but unsure how to } \\
\text { proceed, reduced trust in } \\
\text { science }\end{array}$ & $\begin{array}{l}\text { Questions own values and } \\
\text { behaviour, some understanding } \\
\text { that context may be important } \\
\text { but confused about how to deal } \\
\text { with this }\end{array}$ \\
\hline $\begin{array}{l}\text { 3. Contextual } \\
\text { relativism }\end{array}$ & $\begin{array}{l}\text { Understanding the need for } \\
\text { judgment in data interpretation } \\
\text { and that not all selective data } \\
\text { use is fraud, more critical of } \\
\text { scientific knowledge, } \\
\text { recognizes the role of evidence }\end{array}$ & $\begin{array}{l}\text { Applies new understanding of } \\
\text { distal science to own learning, } \\
\text { perception of self as a scientist, } \\
\text { learning to use judgment and } \\
\text { apply ethical standards }\end{array}$ \\
\hline $\begin{array}{l}\text { 4. } \begin{array}{l}\text { Commitment } \\
\text { within } \\
\text { relativism }\end{array} \\
\text { Critique of culture of science }\end{array}$ & $\begin{array}{l}\text { Critique of the education } \\
\text { system }\end{array}$ \\
\hline
\end{tabular}


Figure 1: Major transitions in the Perry scheme of ethical and intellectual development. Perry's original nine positions can be grouped into four major categories separated by significant transitions, based on Moore (2002).

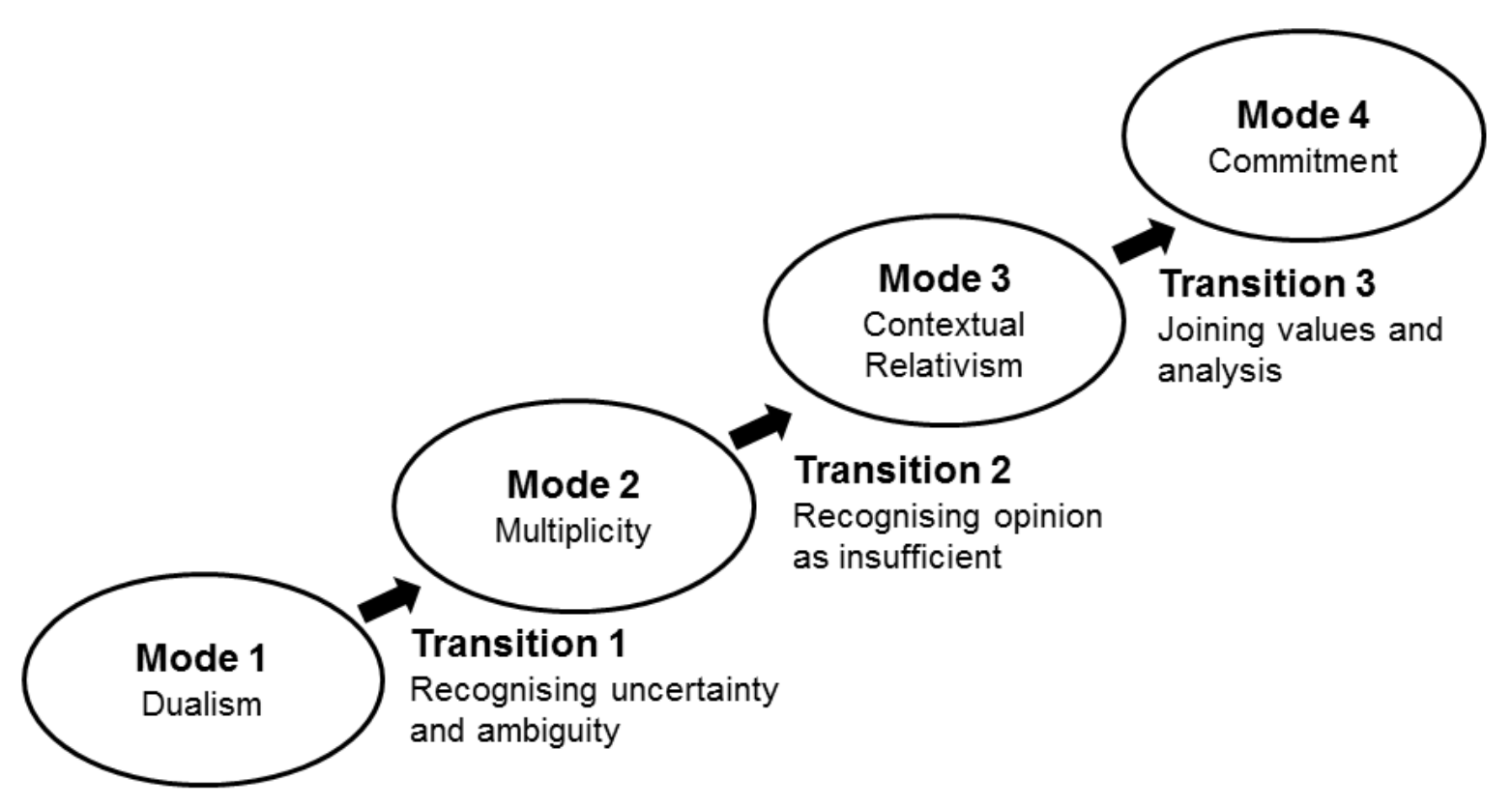


Figure 2: Relationships between levels of sophistication and separation of proximal and distal views

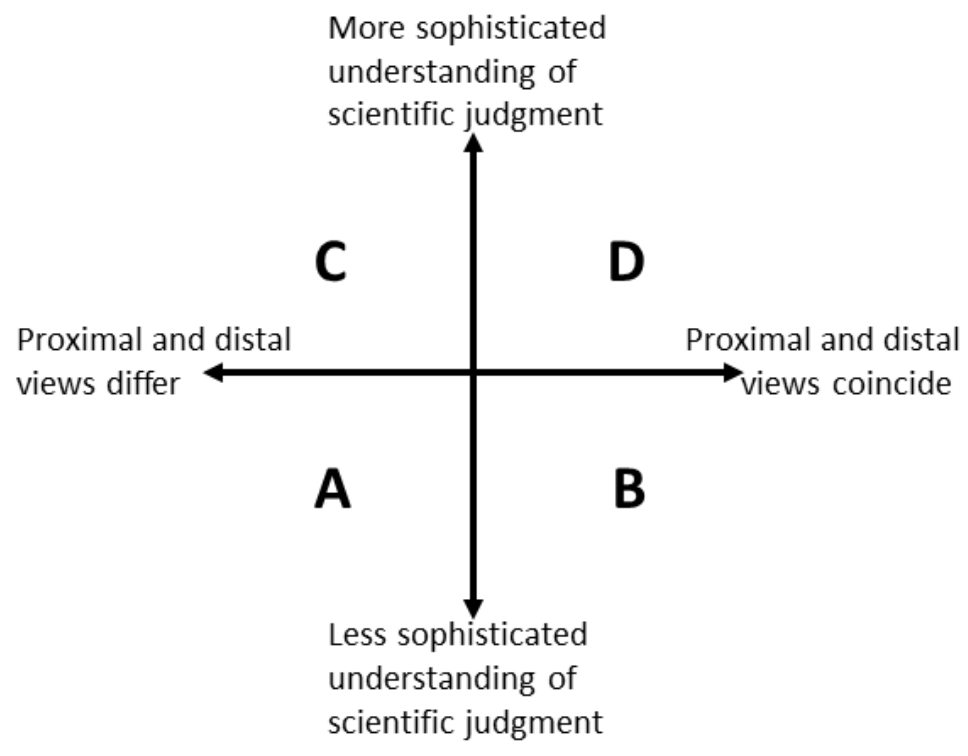

